This item was submitted to Loughborough's Research Repository by the author.

Items in Figshare are protected by copyright, with all rights reserved, unless otherwise indicated.

\title{
Optimization of postbuckled stiffened panels with multiple stiffener sizes
}

PLEASE CITE THE PUBLISHED VERSION

http://www.aiaa.org/

\section{PUBLISHER}

(C) American Institute of Aeronautics and Astronautics (AIAA)

\section{VERSION}

AM (Accepted Manuscript)

\section{LICENCE}

CC BY-NC-ND 4.0

\section{REPOSITORY RECORD}

Watson, Andrew, Carol A. Featherston, and David Kennedy. 2011. "Optimization of Postbuckled Stiffened Panels with Multiple Stiffener Sizes”. figshare. https://hdl.handle.net/2134/8679. 
This item was submitted to Loughborough's Institutional Repository (https://dspace.lboro.ac.uk/) by the author and is made available under the following Creative Commons Licence conditions.

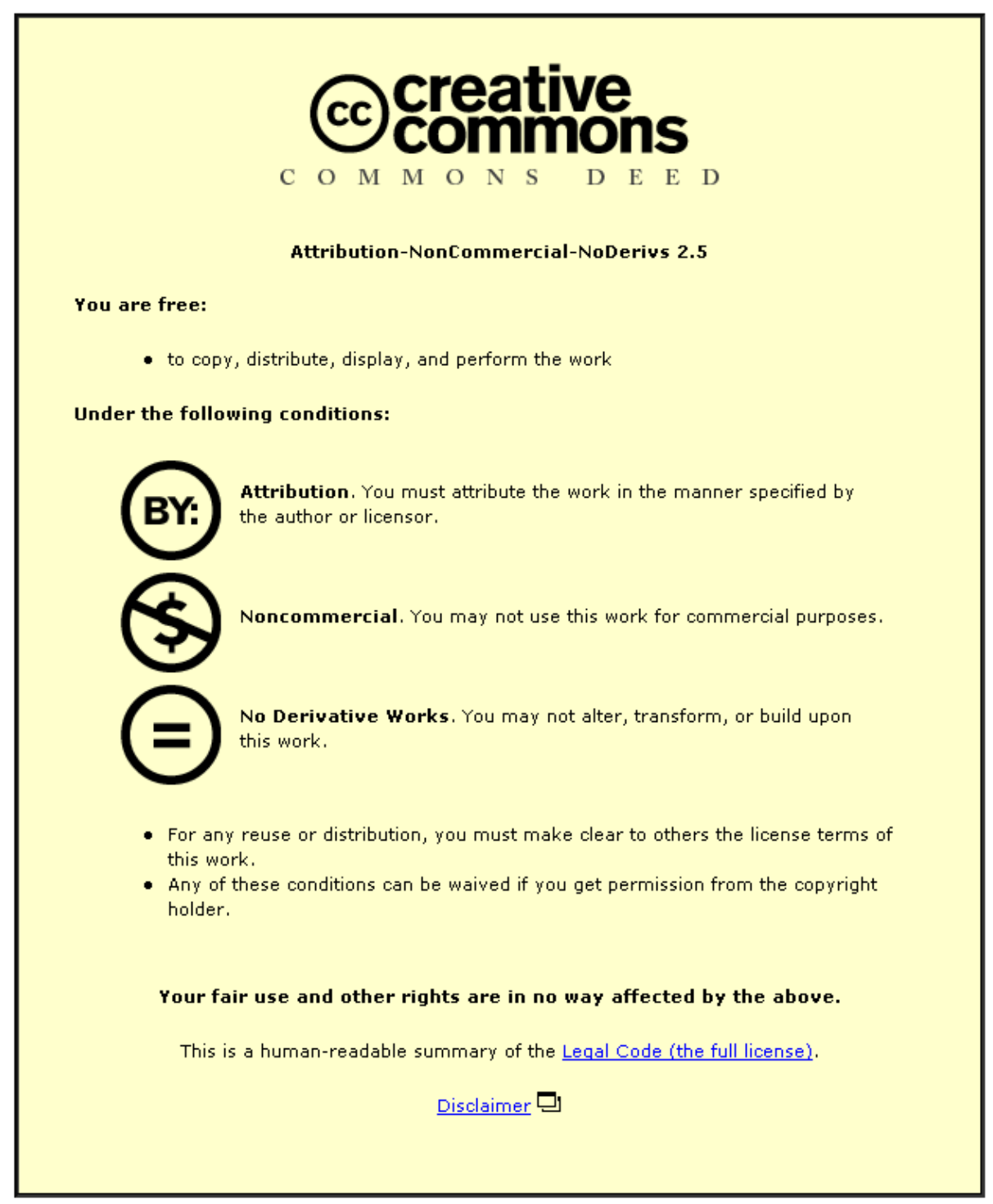

For the full text of this licence, please go to: http://creativecommons.org/licenses/by-nc-nd/2.5/ 


\title{
Optimization of Postbuckled Stiffened Panels with Multiple Stiffener Sizes
}

\author{
Andrew Watson ${ }^{1}$ \\ Loughborough University, Loughborough, LE11 3JT, UK \\ and \\ Carol A. Featherston ${ }^{2}$ and David Kennedy ${ }^{3}$ \\ Cardiff University, Queen's Buildings, The Parade, Cardiff CF24 3AA, UK
}

\begin{abstract}
The panel analysis and optimization code VICONOPT, based on exact strip theory, is utilized to investigate the optimum design of stiffened panels with multiple stiffener sizes or substiffeners. The optimization ensures that the buckling stability of the panel includes an allowance for postbuckling reserve of strength. The adoption of this approach necessarily results in the local buckling stress being lower than the overall buckling stress and with the introduction of substiffeners introduces extra buckling modes. This complicates the post buckling behavior of the panel which is investigated by examining the case when the smaller stiffeners lose stiffness, i.e. there is a change from a local to a torsional mode. The panels are loaded in axial compression with a sinusoidal imperfection. It is found that small mass savings are achieved by using stiffeners of more than one size and there is an increase in the spacing of the major stiffeners and transverse supports. The optimum panel designs obtained by VICONOPT are evaluated by comparison with the optimum designs produced with one size of stiffener.
\end{abstract}

\section{Introduction}

STIFFENED panels in aerospace applications can have a considerable postbuckling reserve of strength, enabling them to remain in stable equilibrium under loads in excess of their critical buckling load, provided the initial buckling mode is local, i.e. not if it is an overall or Euler mode. Other work ${ }^{1,2}$ has shown that it is possible to reduce panel mass by allowing for stiffened panels to have stiffener sizes of more than one size but not considering postbuckling reserve of strength. The aim of this work therefore is to combine these considerations to produce optimum panels that have more than one size of stiffener and low mass when compared to stiffened panels with one size of stiffener with allowance made for postbuckling reserve of strength in the design.

There is an extensive literature on the postbuckling of plates ${ }^{3}$, covering empirical work, experiments and analytic solutions including finite element and finite strip methods. Optimum design techniques have been developed to produce minimum mass designs for a given loading which allow for post-buckling strength ${ }^{4,5}$ and may even consider the possibility of mode jumping ${ }^{6,7}$.

Aircraft performance and life cycle costs are two aspects which put great emphasis on mass minimization of aerospace structures. Early optimization procedures based on initial buckling, stress or strain, and stiffness constraints typically resulted in an idealized structural configuration with very close or equal critical loads for local and overall buckling. Subsequent work showed that this was highly unstable and resulted in panels with unstable postbuckling behavior owing to modal interaction, in which the overall bending stiffness is reduced by local postbuckling deformations, possibly leading to sudden failure of the structure ${ }^{8}$.

In this paper the panel analysis and optimization code VICONOPT, based on exact strip theory, is utilized to investigate the optimum design of stiffened panels with multiple stiffener sizes and a postbuckling reserve of strength. Postbuckling reserve of strength is allowed for by making use of a recent extension to the VICONOPT code implemented by Anderson ${ }^{3}$. The use of this option results in a panel with an initial buckling mode where skin

\footnotetext{
${ }^{1}$ Lecturer, Department of Aeronautical and Automotive Engineering, Member AIAA.

${ }^{2}$ Senior Lecturer, Cardiff School of Engineering.

${ }^{3}$ Reader, Cardiff School of Engineering, Senior Member AIAA.
} 
buckling occurs first and which under further axial loading fails typically in an overall or Euler buckling mode. For panels stiffened with ' $\mathrm{T}$ ' or ' $\mathrm{J}$ ' stiffeners there is an intermediate torsional buckling mode in addition to the skin and overall modes. For panels with two stiffener sizes an extra or new mode is introduced. In addition to the panel optimization investigation an approximate model is put forward to represent the torsional buckling of the small stiffener to demonstrate the postbuckling stability of the panel in this mode. The VICONOPT ${ }^{9}$ code has been shown to give satisfactory panel designs when analyzed using the non-linear finite element analysis computer code ABAQUS ${ }^{10}$. The analysis showed good agreement with the initial buckling behavior and collapse behaviour of optimized panels predicted by VICONOPT ${ }^{11,12}$.

In their recent paper Bushnell and Rankin ${ }^{2}$ reported on the enhancement of the computer program PANDA2 to permit the optimization of flat and/or cylindrical panels and shells with substiffeners. The authors then used the code to find the minimum weight designs of cylindrical shells with T-shaped stringers and rectangular substringers. A previous investigation by Williams ${ }^{1}$, into the optimization of stiffened panels with multiple stiffener sizes, made no allowance for the postbuckling reserve of strength and the local and overall buckling stresses for the optimum designed panel were coincident. An extension of the work of Williams ${ }^{1}$ to allow for postbuckling strength is thus timely and novel.

The next section of the paper will discuss the theoretical background of the computer code.

\section{Theoretical Background to VICONOPT}

VICONOPT $^{9}$ (VIPASA with CONstraints and OPTimisation) is a FORTRAN 77 computer program that incorporates the earlier programs VIPASA (Vibration and Instability of Plate Assemblies including Shear and Anisotropy) and VICON (VIPASA with CONstraints). It covers any prismatic plate assembly, i.e., panels of constant cross section, composed of anisotropic plates each of which can carry any combination of uniformly distributed and longitudinally invariant in-plane stresses. It can be used as either an analysis or an optimum design program. The analysis principally covers the calculation of eigenvalues, i.e., the critical load factors in elastic buckling problems or the natural frequencies in undamped vibration problems. The analysis is based on the exact solution of the governing differential equations of the constituent members, which are assumed to undergo a deformation that varies sinusoidally to infinity in the longitudinal direction, yielding exact stiffness matrices whose elements are transcendental functions of the load factor or frequency and the axial half-wavelength, $\lambda$, of the deformation. The resulting transcendental eigenproblem requires an iterative solution which is performed using the Wittrick-Williams algorithm $^{13}$. The simplest form of the buckling analysis is performed over a range of values of $\lambda$ that usually extends from a value less than the smallest plate width to the length, $l$, of the panel. The lowest buckling load found for any $\lambda$ is taken as the critical buckling load for the panel. This implies that the panel of length $l$ is simply supported at its ends with warping of the entire cross-section allowed.

The extension to the code to allow for postbuckling strength is discussed elsewhere ${ }^{5}$ The new features introduced as a result of the extension are discussed here to aid the reader. To make use of the extension the code requires the input from the user of two parameters, $r_{\mathrm{L}}$ and $r_{\mathrm{s}}$. At initial skin buckling there is a redistribution of the stresses, and the parameter $r_{\mathrm{L}}$ is the user specified fraction of the design load at which skin buckling occurs. Hence prior to skin buckling there is a uniform stress distribution and post initial buckling the stress distribution is non uniform and the skin plates (the user is required to designate which plates precipitate buckling) have a reduced stiffness. The postbuckled stiffness of the buckled plates has the user specified reduced value $r_{\mathrm{s}}$. Typically a value of $r_{\mathrm{s}}=0.5$ is used for metal plates. It should be noted that (although not used in this paper) a further extension enables the VICONOPT code to calculate automatically the postbuckled stiffness of each plate. Allowance is made for an initial imperfection in the plates that are optimized in this paper.

The VICONOPT optimization procedure ${ }^{9}$ consists of design cycles, in each of which constraints, sensitivities and move limits are calculated and used in a linear optimization step, which is normally and ideally followed by a stabilization step. The set of constraints can include buckling, material and configurational constraints. The buckling sensitivities are calculated by perturbing each eigenvalue and measuring the change in the buckling load. The linear optimizer gives designs which are only approximate because the constraint information it receives is linearized at the design configuration at which the cycle starts, whereas the true optimization problem has non-linear constraints. The stabilization step makes the design just stable by scaling all the design variable thicknesses that are not restricted by bounds. This step is omitted when the restriction to available gauge thicknesses only prevents the thicknesses from being scaled. The design load when using the postbuckling option (i.e. allowing for skin buckling to occur before the design load) is taken as the collapse or failure load.

In addition to allowing for postbuckling reserve of strength the aim of this work is to investigate the optimum design of panels with more than one stiffener size. Therefore the next section of the paper will start with an 
examination of the possible different buckling modes for stiffened panels, proceed to discuss the reasons for using more than one stiffener size, explore how to size the small stiffeners, and investigate the overall stability of the panel when the stiffness of the small stiffener has been reduced.

\section{Buckling Modes of Stiffened Panels}

The buckling modes of stiffened panels fall into three broad categories, local, torsional and overall modes. Figure 1 shows the cross section of an isotropic, rectangular panel with two different sizes of stiffener, which is loaded in longitudinal compression. Figure 2 shows the relationship between its critical buckling stress and longitudinal half-wavelength $\lambda$. The buckling stresses were obtained by using the VIPASA ${ }^{13}$ option in VICONOPT. The buckling modes show the characteristics of each of four mode shapes for the lowest eigenvalues only.

The distinguishing features for each mode can be seen in Fig. 2. For overall modes the longitudinal line junctions between the stringer webs and the skin displace and therefore are not straight, and in practice there is one half wave across the width which looks similar to a half sine wave. In torsional and local modes the web/skin line junctions do not displace and therefore remain straight to first order accuracy. The difference between these two modes depends on whether the flanges of the stiffeners are sufficiently stiff to keep the line junctions between the flanges and webs essentially straight or not.

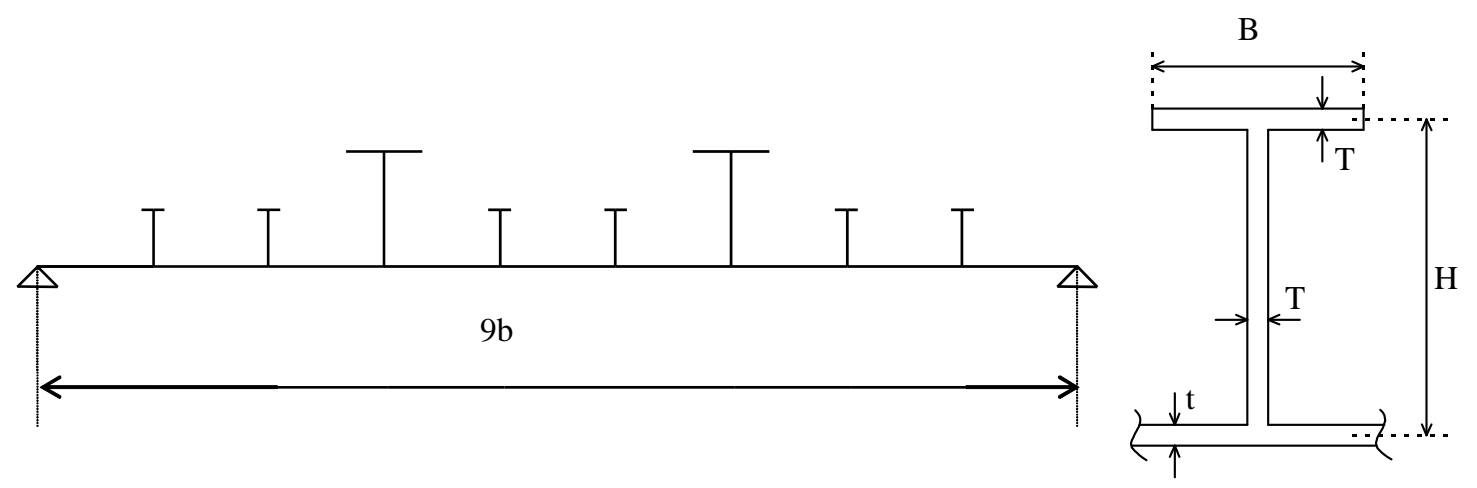

Figure 1: Cross section of prismatic stiffened panel. The stiffener pitch is $b, b / t=30$, and the large stiffeners have $T=t, H=b$ and $B=2 b / 3$, while $T=0.6 t, H=b / 2$ and $B=b / 5$ for the small stiffeners. The panel is simply supported on all four edges.

Panels having two different stiffener sizes or types exhibit an additional type of buckling mode, denoted 'partial overall'. Consider the panel with two stiffener sizes shown in Figure 1. If the small stiffener is not large enough then this mode will resemble that shown as mode $\mathrm{C}$ in Fig. 2, i.e. partial overall. In terms of the large stiffener, this is a torsional mode because the web/skin line is straight and the flange/web line is not, but as far as the small stiffeners are concerned, it is an overall mode. Hence it can be described either as partial overall (i.e. overall for part of the structure), or alternatively as a modified torsional mode of the large stiffeners. Hence the number of intermediate modes is a function of the number of different stiffeners. The stress versus $\lambda$ plots will not necessarily have clearly defined minima for each mode and there may be coupling between modes. For example, see Fig 7 below where for the second mode no minimum is seen but the mode is shown in Fig 6. This will be discussed later with reference to the work of Williams who optimized a panel with alternating ' $T$ ' and blade stiffeners and showed mass savings compared to a panel optimized with the same number of stiffeners which were identical. If the large stiffener (or largest in the case of multiple stiffener sizes) is of sufficient size it is possible to create an overall mode that has more than one half wavelength in the transverse direction. These large stiffeners are sometimes referred to as panel breakers since the panel mode or overall mode is prevented. Examples of panels designed in this way can be found in aerospace structures.

In the work of Bushnell ${ }^{2}$ panels with substiffeners were presented where the substiffener had a rectangular cross section and the large stiffener could be of any cross section. This investigation did not allow for local postbuckling. The aim of the paper was to determine if the minimum weight designs of the optimized panels and shells were lighter than those optimized with just $\mathrm{T}$ shaped stiffeners. . The computer code PANDA2 ${ }^{14}$ was enhanced to permit the adding of substiffeners with rectangular cross sections. 

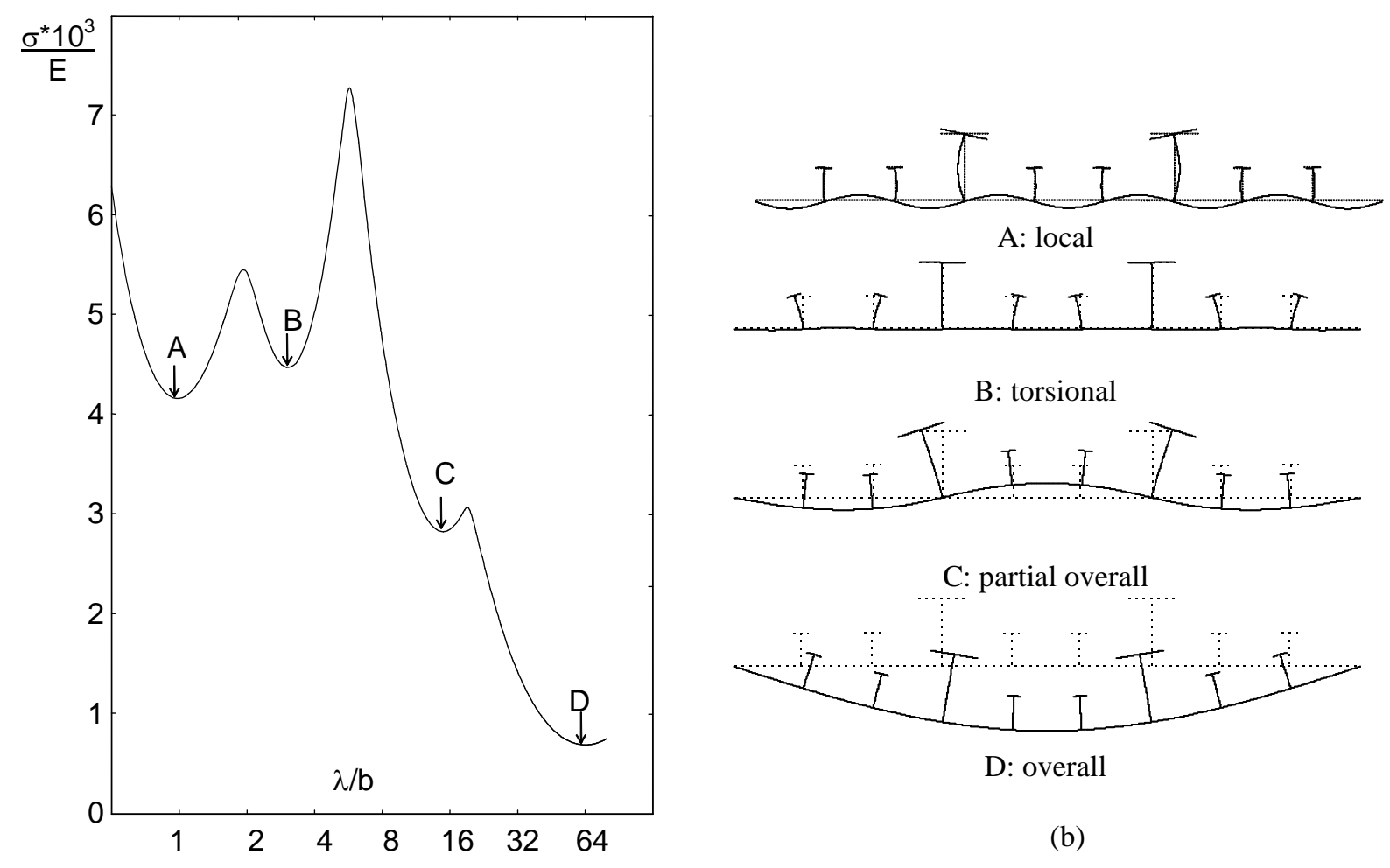

A: local
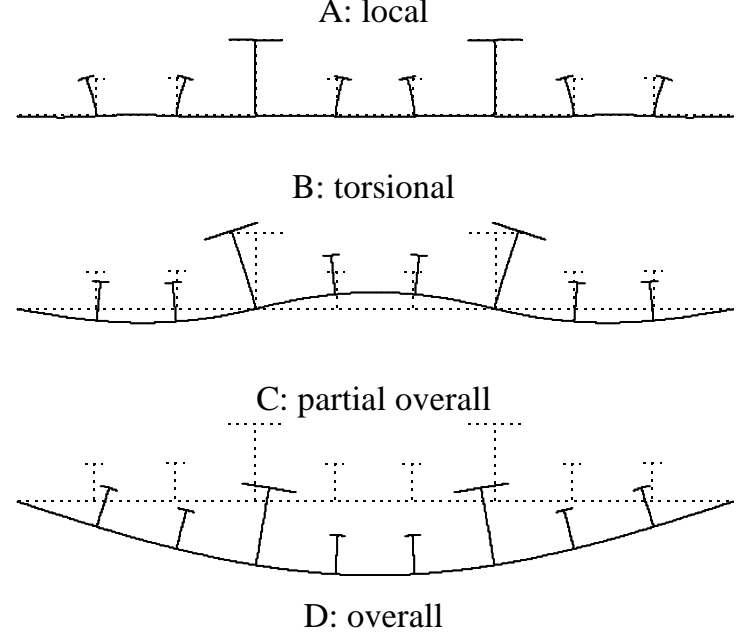

(b)

(a)

Figure 2 (a) Plots of buckling stress $\sigma$ for the panel of Fig. 1 and (b) the computed buckling modes for the four points A, B, C and D. The graph shows only the lowest buckling stress for each half-wavelength $\lambda$. Each of the four regions $A, B, C, D$ has a particular mode shape and the buckling modes in each region are shown. The mode shapes are shown solid with the panel cross section in its original position in dashed lines. Note mode C can be considered torsional buckling of the small stiffener.

\section{Mass Savings with Alternating Stiffener Sizes}

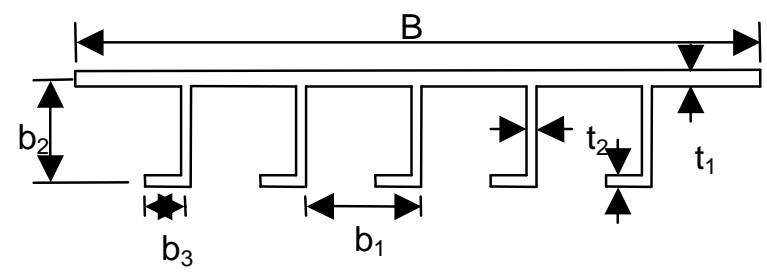

Figure 3. Stiffened panel of Anderson
In his work to extend the capabilities of VICONOPT Anderson presented results showing the effect of buckling load and postbuckling stiffness on the mass of aluminum panel with Young's modulus $10.5 \times 10^{6} \mathrm{psi}$, Poisson's ratio 0.32 and density $0.1 \mathrm{lb} \mathrm{in}^{-3}$. The panel examined in this work is shown in Fig. 3 and had the following design conditions. All edges were simply supported. The axial load was $45000 \mathrm{lb}$. The panel length and width (B) were 30 inches, and there was a sinusoidal imperfection of amplitude 0.03 inches The stiffener pitch $b_{1}$ was held constant at 5 inches. The design variables were the web breadth $b_{2}$, flange breadth $b_{3}$, the skin thickness $t_{1}$ and the stiffener thickness $t_{2}$. The results of this optimization are shown in Table 1 . The optimization has been extended so that a new panel optimization can be considered. In this second case the stiffeners are no longer identical. Alternating stiffeners are assumed identical; thus the leftmost, rightmost and central stiffeners have linked design variables, while the remaining two are linked and vary independently of the 
other three. The outcome of the optimization is included in Table 1 which shows mass savings are possible by allowing for different stiffener sizes.

Table 1. Mass in lbs for optimized panel of Anderson. The table shows the effect of buckling load and postbuckling stiffness on the mass of an aluminum $Z$ stiffened panel. The results of an all identical stiffener stiffener arrangement are compared to those of an alternating arrangement.

\begin{tabular}{cccc}
\hline \hline Identical & & & \\
Stiffeners & & & \\
\hline & & $\mathbf{r s}$ & \\
$\mathbf{r}_{\mathrm{L}}$ & $\mathbf{3}$ & $\mathbf{. 5}$ & $\mathbf{. 7}$ \\
$\mathbf{1}$ & 10.7 & 10.5 & 10.1 \\
$\mathbf{. 7}$ & 9.71 & 9.58 & 9.18 \\
$\mathbf{. 4}$ & 8.85 & 8.36 & 8.02 \\
$\mathbf{. 1}$ & 7.94 & 7.82 & 7.63 \\
& & & \\
\hline Alternating & & & \\
Stiffeners & & & \\
\hline & & $\mathbf{r s}$ & \\
$\mathbf{r}_{\mathrm{L}}$ & $\mathbf{3}$ & $\mathbf{. 5}$ & $\mathbf{. 7}$ \\
$\mathbf{1}$ & 10.3 & 10.1 & 10.0 \\
$\mathbf{. 7}$ & 9.32 & 9.36 & 9.06 \\
$\mathbf{. 4}$ & 8.33 & 8.22 & 7.84 \\
$\mathbf{. 1}$ & 6.92 & 6.65 & 6.93 \\
\hline \hline
\end{tabular}

The cross section of one of the optimized designs of Table 1 is shown in Fig. 4. It should be stated that the outside skin portions are of the same breadth as the inter stiffener skin portions. For such arrangements with identical stiffeners local buckling would be precipitated in these outside portions of skin since the longitudinal line supports do not supply any rotational constraint whereas the stiffeners do. Hence it is more common to see panels with the two outside skin portions approximately half the value of stiffener pitch. This layout therefore is seen to have pushed the design in the direction shown in Fig. 4 which has large outside stiffeners while the adjacent two stiffeners towards the center are small. The stress versus $\lambda$ plot, not shown here, for this optimized panel does not have the four distinct portions shown in Fig 2. The only minima are for the modes $\mathrm{A}$ and $\mathrm{C}$ i.e. local and partial overall. The mode D is not seen for the panel configuration with a length of 30 inches. Mode B is seen when examining the cross section mode plots but there is interaction of this mode with both the local mode $\mathrm{A}$ and torsional mode $\mathrm{C}$. At half-wavelengths between 6 and 10 inches there is tripping of the small stiffener and local buckling of the large stiffener. At halfwavelengths between 10 and 15 inches there is coupling between tripping of both the two stiffener sizes. At longer half-wavelengths, i.e. greater than 15 inches, the web of the small stiffener displaces in plane and the mode switches to pure mode $\mathrm{C}$.

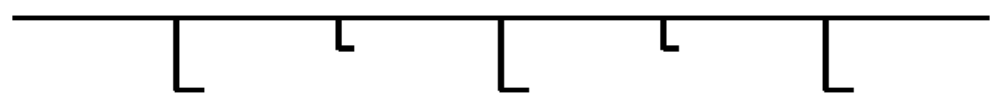

Figure 4. Optimized alternating stiffened panel of Table 4 with $r_{L}=0.7$ and $r_{s}=0.5$.

\section{Optimization of Panel with Alternating Stiffener Sizes}

The cross section of the identical stiffener and alternating stiffener panels optimized by Williams ${ }^{1}$ are shown in Figure 5. The identical stiffener panel has skin thickness $t$, stiffener thickness $0.75 t$, web height $22.5 t$ and flange breadth 18t. For the alternating panel the skin and blade stiffener have thickness $1.035 t$, the ' $\mathrm{T}$ ' stiffener has thickness $0.912 t$, total flange breadth is $21.2 t$ and large web height is $26.5 t$. Both panels have stiffener pitch $30 t$ and total width 280t. The alternating panel has four different buckling modes. However the small stiffener blade mode $B$ is one where the web deflects in plane and can be seen in Fig. 6 . The actual stress versus $\lambda$ plot shows that mode $B$ is not a critical mode, and modes $C$ and $D$ are very close to the local buckling stress value. The part of the stress versus $\lambda$ curve associated with mode $B$ is coupled with mode $C$ and hence does not have a distinct minimum. The alternating panel had a lower mass $(6.7 \%)$ than the identical panel. Figure 7 shows the stress versus $\lambda$ plot for the alternating panel and it can be seen that the critical stresses for modes A, C and D have similar values. This stemmed from the design procedure which was a compromise between local and overall buckling requirements. The requirements for local buckling were: 
(i) There must be enough stiffeners to prevent buckling of the skin between stiffeners; and

(ii) All component plates of the stiffeners must be adequately thick.

The overall buckling requirement was an adequate second moment of area which is most easily achieved when:

(iii) Only a few stiffeners are used; and

(iv) The stiffeners are very thin.

It is seen that the local buckling constraints conflict with the overall buckling constraints, which leads to a panel design with coincident local and overall buckling stresses. Such panels have no postbuckling reserve of strength, and may fail at a stress below the local or overall buckling stress. Making use of Anderson's extensions to VICONOPT $^{5}$ it is possible to modify the requirements stated by Williams above, and allow for local postbuckling strength. Hence requirement (i) should be changed to:

(i) There must be sufficient stiffeners to prevent buckling of the skin between stiffeners at a specific fraction of the design load.
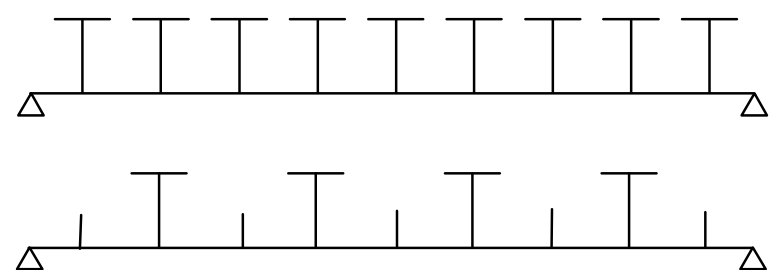

Figure 5. Identical and alternating stiffener panels of Williams

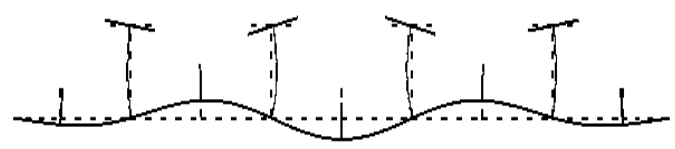

Figure 6. Mode B for alternating panel

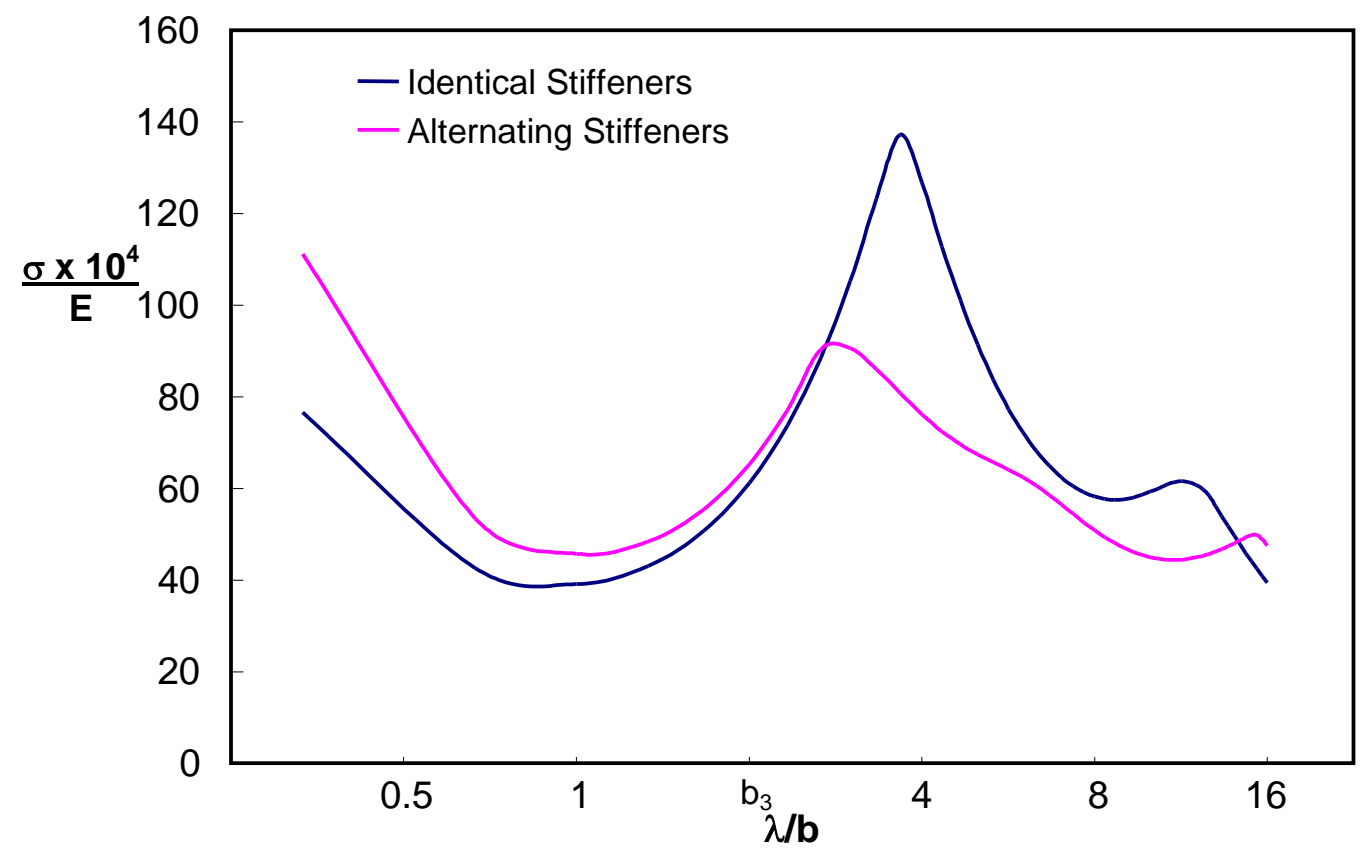

Figure 7. Stress versus $\lambda$ plot for identical and alternating stiffener of Williams 


\section{Optimization of Postbuckled Stiffened Panels with Multiple Stiffener Sizes}

The topology of the panel will dictate the shape of the critical buckling stress versus $\lambda$ curve. It is suggested that an optimum postbuckled stiffened panel with multiple stiffener sizes would ideally result in a stress versus $\lambda$ curve with the lowest critical stress occurring with mode $\mathrm{A}$, increasing to mode $\mathrm{B}$, then mode $\mathrm{C}$ and finally mode $\mathrm{D}$.

For a panel designed in such a way there would be have to be a rigorous postbuckling analysis to account for secondary postbuckling behavior. Mass optimization of stiffened panels designed for service in the local postbuckling regime can also lead to behavior dominated by mode interactions such as mode jumping ${ }^{4,5,15}$. Hence a mode change from mode A to mode B may become possible. For mode B, e.g. in plane buckling of a blade, then the postbuckling behavior can be determined. An approximate method to analyse this would be to smear out the small stiffener and effectively have a thicker skin. The postbuckling behavior of this new flat plate between stiffeners is reasonably stable, although it would be necessary to check that the reduction in the overall stiffness has not adversely affected the overall buckling requirement.

Mode jumping behavior normally involves an increase of one in the number of half-wavelengths with the same mode type. Hence to jump from mode A to mode B which can be considered a local mode of the large stiffener may not be possible since the wavelengths associated with mode B are longer than those of mode A. At each mode change the overall stability of the panel needs to be checked.

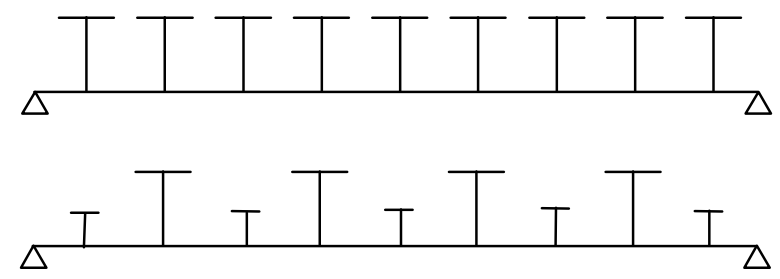

Figure 8. Identical and alternating stiffener panels

The two panels of Fig. 8 were optimized with VICONOPT with the parameters $r_{L}=0.7$ and $r_{s}=0.5$. Hence the local buckling was to be specified to occur at 0.7 of the design load. The optimized panels had masses of $7.84 \mathrm{~kg}$ and $8.54 \mathrm{~kg}$ for the alternating and identical stiffener cross sections respectively, i.e. an $8.2 \%$ mass saving is achieved by using alternating stiffener sizes. The panel length is $0.762 \mathrm{~m}$ and the total width $1.27 \mathrm{~m}$. The same loading per unit width as the panel of Anderson was used. All skin portions were fixed at $127 \mathrm{~mm}$ and an initial imperfection of amplitude $l / 1000$ was included.

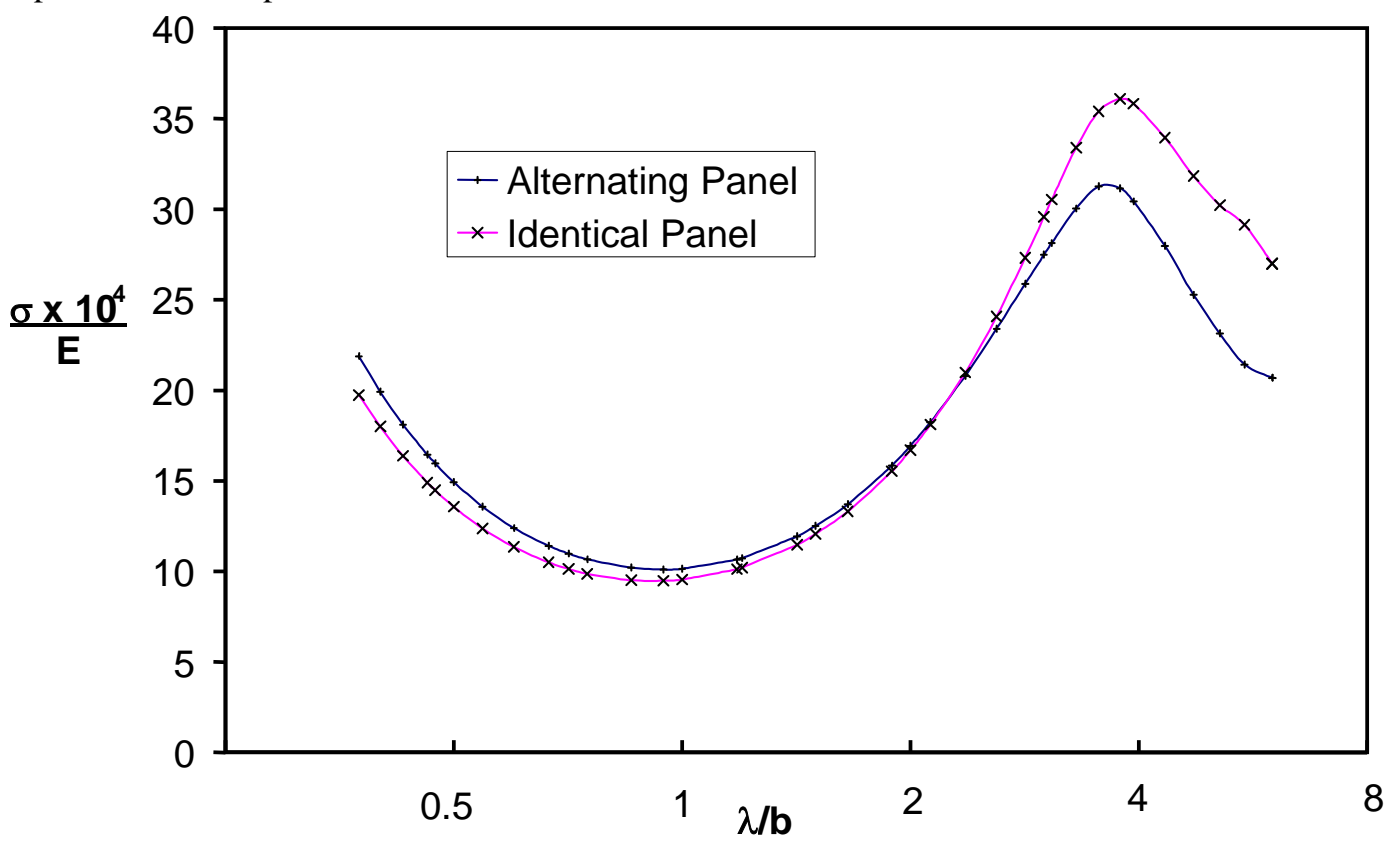

Figure 9. Stress versus $\lambda$ plot for identical and alternating stiffener of Williams 
The plot of stress versus $\lambda$ is shown in Fig. 9 for both types of panel. The postbuckling reserve for the identical panel is larger than that of the alternating panel. Typical aerospace panels are designed so that initial buckling does not occur too early in the loading regime. The mode for $\lambda=l$ is a type $\mathrm{C}$ mode. Hence the curve has at most three minima. However due to coupling, modes of type B do not form a distinct curve. For the alternating panels seen in this paper mode B was not easily identifiable, compared (for example) with the panel shown in Fig 1 which does not have a alternating set up. Hence the local postbuckling behavior of the alternating panel is one where skin postbuckling behavior is followed by collapse without mode change to other modes such as mode B. Mode jumping from one skin type to another skin type mode is allowed for.

\section{Conclusion}

The aim of this work was to identify possible mass savings for panels optimized with alternating stiffener sizes and where the panel had stable local postbuckling behavior. This has been demonstrated and it is suggested that the postbuckling behavior of such panels is not complicated by changes to other types of mode but does allow for mode jumping to other buckling modes of the same type.

\section{References}

${ }^{1}$ Williams, F.W., "Stiffened Panels with Varying Stiffener Sizes", Journal of the Royal Aeronautical Society, Vol. 77, No. 751, July, 1973, pp 350-354.

${ }^{2}$ Bushnell, D. and Rankin, C.C., "Optimum Design of Stiffened Panels with Substiffeners" Proceedings of 46th AIAA/ASME/ASCE/AHS/ASC Structures, Structural Dynamics, and Materials Conference, Austin, TX, 2005, pp. 1587-1640.

${ }^{3}$ Hutchinson, J.W., and Koiter, W.T., "Postbuckling Theory," Applied Mechanics Reviews, Vol. 23, 1970, pp. $1353-1366$.

${ }^{4}$ Bushnell, D., "Optimization of Composite, Stiffened, Imperfect Panels Under Combined Loads for Service in the Postbuckling Regime," Computer Methods in Applied Mechanics and Engineering, Vol. 103, 1993, pp. 43-114.

${ }^{5}$ Anderson, M.S., "Design of Panels Having Postbuckling Strength," Proceedings of 38th AIAA/ASME/ASCE/AHS/ASC Structures, Structural Dynamics, and Materials Conference, Kissimmee, FL, 1997, pp. 2407-2413.

${ }^{6}$ Everall P.R. and Hunt G.W. "Arnold Tongue Predictions of Secondary Buckling in Thin Elastic Plates", Journal of the Mechanics and Physics of Solids, Vol. 476, No. 10, 1999, pp.2187-2206.

${ }^{7}$ Bushnell D., Rankin C.C. and Riks, E., "Optimization of Stiffened Panels in Which Mode Jumping is Accounted For", Proceedings. of 38th AIAA/ASME/ASCE/AHS/ASC Structures, Structural Dynamics, and Materials Conference, Kissimmee, FL, 1997, pp. 2123-2162.

${ }^{8}$ Hunt, G.W., "An Algorithm for the Non-linear Analysis of Compound Branching," Philosophical Transactions of the Royal Society of London., Vol. A300, No. 1455, 1981, pp. 443-471.

${ }^{9}$ Butler, R., and Williams, F. W., "Optimum Design Using VICONOPT, a Buckling and Strength Constraint Program for Prismatic Assemblies of Anisotropic Plates," Computers and Structures, Vol. 43, No. 4, 1992, pp. 699-708.

${ }^{10}$ Hibbitt, Karlsson, and Sorensen, Inc., ABAQUS/Standard User's Manual, Version 5.7, Pawtucket, RI, 1997.

${ }^{11}$ Lillico, M., Butler, R., Hunt, G. W., Watson, A., Kennedy, D., and Williams, F. W., "Analysis and Testing of a PostBuckled Stiffened Panel,” AIAA Journal, Vol. 40, No. 5, 2002, pp. 996-1000.

${ }^{12}$ Lillico, M., Butler, R., Hunt, G. W., Watson, A., and Kennedy, D., "Postbuckling of Stiffened Panels Using Strut, Strip, and Finite Element Methods," AIAA Journal, Vol. 41, No. 6, 2003, pp. 1172-1179.

${ }^{13}$ Wittrick, W. H., and Williams, F. W., "Buckling and Vibration of Anisotropic or Isotropic Plate Assemblies Under Combined Loadings,” International Journal of Mechanical Sciences, Vol. 16, No. 4, 1974, pp. 209-239.

${ }^{14}$ Bushnell, D., "PANDA2 - program for minimum weight design of a stiffened, composite, locally buckled panels", Computers and Structures, Vol. 25, No. 4, 1987, pp. 469-605.

${ }^{15}$ Watson, A. and Kennedy, D. "Mode Jumping in Post-buckled Stiffened Panels", International Conference on Thin-walled Structures, Loughborough, UK, 2004, pp. 573-580. 